\title{
Recurrence rate of superficial bladder cancer with intravesical BCG and mitomycin.
}

1. MBBS, MS (Urology) Professor Urology

Gujranwala Medical College, Gujranwala.

2. MBBS, MS (Urology)

Assistant Professor Urology M. Islam Medical College and Teaching Hospital Gujranwala

3. MBBS, MS (Urology) Senior Registrar Urology Sir Ganga Ram Hospital, Lahore.

4. MBBS, M.Phil (Pathology)

Assistant Professor Pathology

Aviccena Medical College, Lahore.

5. MBBS

Post graduate Resident Urology Gujranwala Medical College, Gujranwala.

6. MBBS, MS (Urology) Assistant Professor Urology DHQ Teaching Hospital Gujranwala/ Gujranwala Medical College, Gujranwala.

Correspondence Address:

Dr. Khalid Hussain

Department of Urology

Gujranwala Medical College,

Gujranwala.

khaliduro@yahoo.com

Article received on:

28/05/2020

Accepted for publication:

18/02/2021
Khalid Hussain ${ }^{1}$, Muhammad Asif ${ }^{2}$, Farooq Malik ${ }^{3}$, Munazza Yasmeen ${ }^{4}$, Maria Tariq ${ }^{5}$, Attiq-ur-Rehman Khan ${ }^{6}$

ABSTRACT... Objective: To compare the recurrence rate of superficial transitional cell carcinoma of urinary bladder using intravesical BCG and Mitomycin-C. Study Design: Randomized Controlled Trial. Setting: Urology Department, Teaching DHQ Hospital, Gujranwala. Period: November 2018, to Sep, 2019. Material \& Methods: Was carried out on total 270 patients, admitted with suspicion of urothelial tumors. They were grouped in Group A and B, comprising 135 in each group. Group A received BCG and Group B received Mtiomycin-C intravesically following TUR-BT. Results: Out of 270 patients male to female ratio was 3:1. Age range of patients was between 30 to 70 years with mean of $50.0 \pm 13.1$ and $552.3 \pm 12.9$ years in Group $A$ and $B$ respectively. Recurrence was noted in $05.38 \%$ and $15.38 \%$ patients in Group A and B respectively. Regarding side effects pyrexia was associated with BCG in $27.40 \%$ patients which were self-limited in $26.66 \%$ cases however required anti-tuberculosis therapy for six months in $0.74 \%$. Whereas only $06.67 \%$ patients receiving Mitomycin had pyrexia. Dysuria occurred in $74 \%$ and frequency in $68 \%$ patients who received BCG. Whereas Dysuria occurred in $20 \%$ and frequency in $36.29 \%$ patients who received Mitomycin-C. However genital skin rash was more common (08.14\%) in Mitomycin group than BCG. Conclusion: Keeping in mind less recurrence rate and bearable toxicity, it is concluded that BCG is superior to Mitomycin. This study suggests long term follow up is required to establish recurrence in the management of superficial bladder cancer.

Key words: $\quad$ Intravesical BCG, Mitomycin-C, Superficial Transitional Cell Carcinoma of Urinary Bladder.

Article Citation: Hussain K, Asif M, Malik F, Yasmeen M, Tariq M, Khan A. Recurrence rate of superficial bladder cancer with intravesical BCG and mitomycin. Professional Med J 2021; 28(6):854-860. https://doi.org/10.29309/TPMJ/2021.28.06.4968

\section{INTRODUCTION}

In the world, bladder cancer is the second commonest occurring urological growth. Several patients of bladder tumor present with superficial transitional cell carcinoma. ${ }^{1}$ The patients with bladder cancer are diagnosed mostly in the age of 65 years and at the moment of diagnosis about $75 \%$ of bladder tumors are localized and $25 \%$ of patients have presentation with regional lymph nodes involvement or distant metastasis. Approximately $90 \%$ are transitional cell carcinoma, adenocarcinoma $<2 \%$ (may be proceeded by cystitis) and squamous cell carcinoma constitutes $5-10 \% .^{2}$

The problem in superficial bladder tumor is its trend to reappear, about 50 to $80 \%$, following surgical ablation alone. Superficial bladder tumor may progress to muscle of urinary bladder in 20 to $25 \%$ cases $^{3}$ and recurrence rate remains high in the first year after transurethral resection of bladder tumor (TUR). ${ }^{4}$ Superficial bladder tumor after transurethral resection (TUR) is known to reappear repeatedly, even in patient who receives intravesical instillation of chemotherapy or immunotherapy. If superficial bladder cancer left untreated after TUR, it will recur within 03 years in $70 \%$ of cases. ${ }^{5}$

The high recurrence rate in non-muscle invasive bladder tumor $(>70 \%)$ is caused by the bond of free floating cancer cells during transurethral resection, by partial resections, by unnoticed and new tumors. Regular follow-ups and resections 
are required. ${ }^{6}$ Superficial bladder tumor is usually managed by transurethral resection along with adjuvant intravesical instillations of chemotherapy or immunotherapy. Adjuvant instillation therapy with chemo or immunotherapeutic agents is an essential element in the management of patient with superficial bladder tumor. ${ }^{7}$

Different chemotherapeutic drugs are available for intravesical instillation; one of them is Mitomycin-C, which is antibiotic alkylating agent. It reduces recurrence and prevents tumor cell implantation on the site of resection and eliminates any residual disease. ${ }^{8}$ After TURBT, a single immediate intravesical instillation of chemotherapy is helpful in reducing recurrence rates as much as $4.5 \%$ at one year as compared to $38.1 \%$ in patients with TUR-BT alone. ${ }^{9}$ Efficacy of mitomycin-C is optimum within 6 hours of resection. The usual optimal contact time of the drug is one hour. ${ }^{8,10}$

Another possibility is the use of intravesical bacillus Calmette Guerin BCG instillation which is considered to be the most useful therapy and prophylaxis for transitional cell carcinoma Ta, $\mathrm{T} 1$, and $\mathrm{CIS}$ and reduces tumors recurrences, disease progression and mortality. At the beginning of $20^{\text {th }}$ century, tuberculosis was noted to have antitumors effect. Pearl performed a series of autopsy at John Hopkins Hospital in 1929 and published a lesser incidence rate of cancer in patients with tuberculosis. Novard isolated Mycobacterium Bovis from a cow with tuberculous mastitis in 1904. During the passage through laboratory the Mycobacterium culture showed strong affinity to cluster. ${ }^{11}$

\section{OBJECTIVE}

To compare the recurrence rate in superficial transitional cell carcinoma of urinary bladder using intravesical instillation of BCG and Mitomycin-C.

\section{MATERIAL \& METHODS}

This randomized trial was carried out on total 270 patients, admitted with suspicion of urothelial tumors. They were grouped in Group A and B, comprising 135 in each group. Group A received $B C G$ and Group B received Mtiomycin-C intravesically following TUR-BT.

Recurrence was defined as reappearance of tumor (confirmed on check cystoscopy and histopathology of biopsy. The inclusion criteria was; all patients of any age, both gender with superficial bladder tumor $\mathrm{Ta}$ (noninvasive papillary carcinoma and T1 (tumor invades sub epithelial connective tissue the lamina propria), Low grade superficial bladder carcinoma and Biopsy confirmed recurrent superficial bladder tumor. Exclusion criteria was; patients with active tuberculosis, Immunocompromised patients (known impaired immune response, positive HIV serology, patients getting steroids/ immunosuppressive therapy, leukocytes count $<3500 / \mathrm{mm}^{3}$, Patients not willing for intravesical therapy and Patients with positive mauntoux negative test.

The patients were clinically evaluated with respect to history, physical examination, cytology, ultrasonography, and intravenous urography. We did trans-urethral resection of bladder tumor (TUR-BT) and deep biopsy was preserved in formalin in separate containers, marked them and sent for histopathology. Diagnosis was confirmed with histopathology. Tumours were graded according to the WHO classification system TNM. The patients age ranged from 30-70 years, regardless of sex with superficial bladder tumour Ta (non-invasive papillary carcinoma and T1 (Tumour invades sub-epithelial connective tissue the lamina propria), Low grade superficial bladder carcinoma, biopsy confirmed recurrent superficial bladder tumour were included in the study.

Patients after staging and grading the tumor and fulfilling the inclusion criteria were randomly allocated into two groups (Group A \& B) by using Open Epi-version software. Group-A was comprised 135 patients randomly allocated for intravesical Onco Tice BCG and advised the patients to come without drinking water from last 6 hours. I put the face mask and wore the hand disposable gloves. Before instillation urinary bladder emptied, BCG 50 mg, (OnCoTice), diluted with $50 \mathrm{ml}$ of saline in bladder wash 
syringe.

Group-B was comprised 135 patients randomly allocated for intravesical Mitomycin-C 40mg. Patients were advised to come without drinking water 6 hours before instillation and explained the procedure and its side effects to patients. I put the face mask and wore the hand disposable gloves. Mitomycin C $40 \mathrm{mg}$, mixed with $50 \mathrm{ml}$ of sterile water in bladder wash syringe.

Cleaned glans penis and OnCo-Tice BCG was administered intravesically after passage per urethral nelton catheter No.14 Fr and patient was instructed to hold the urine for two hours in different positions (supine, prone, right and left lateral). After two hours, according to advice patients emptied bladder in wash room and washed the perineal area also. During Intravesical therapy was given weekly for six consecutive weeks.

Patients came for check cystoscopy every 3 month for 1 year. They were advised to come earlier if they suffered from haematuria, lower urinary tract symptoms or fever. TUR-BT biopsy was carried out if necessary. Recurrence was defined as histological proven recurrence. Side effects were recorded based on patient's complaint, physical examination, mantoux test, blood and urine analysis. OnCo-Tice BCG instillations were stopped in patients with BCG sepsis and anti-tuberculous treatments were started for six months. The patients were followed for one year for recurrence and side effects. The patients were advised to follow up for cystoscopy every 3 months for a period of 2 years, every 4 months in the third year, and every 6 months thereafter until 5 years, and yearly thereafter.

\section{RESULTS}

The study is divided into two groups, Group A and Group B. Each group comprised 135 patients. The mean age of patients in group-A and group-B was $50.0 \pm 13.1$ years and $52.3 \pm 12.9$ years respectively. There were $100(74 \%)$ male and $35(26 \%)$ female patients in Group-A, while 102(75\%) male and 33 (25\%) female patients in Group-B. The number of patients involved in different professions showing that maximum numbers of patients are factory workers $60(22.2 \%)$. In the history of smoking, it was found that smoker male patients were 79 and 70 in both groups A and Group B respectively, while less percentage of female were smoker in both groups.

Painless haematuria was seen in 247 patients and clot retention was observed in 152 patients. 20 patients were presented with the symptoms of urgency and dysuria. Only 3 patients were presented with microscopic haematuria. On cystoscopy, most common site of growth was right lateral wall, $130(48.14 \%)$ patients had tumour on this site. Only in six patients tumor was positioned on Vault. Twenty seven patients presented with multiple tumor on right lateral wall, left lateral wall, posterior wall and bladder neck.

Cystoscopy helped in the size of tumour. One hundred patients showed less than $1 \mathrm{~cm}$ size of tumour. One to two $\mathrm{cm}$ size of growth found in one hundred and twenty nine patients. Only $30.36 \%$ patients showed two to three $\mathrm{cm}$ growth on cystoscopy. In group $\mathrm{A}$, the cystoscopic findings during TUR-BT revealed that $87(64.44 \%)$ of patients has single tumour and $48(35.55 \%)$ has multiple tumours while in Group B, patients with single tumour are $81(60 \%)$ and with multiple 54 (40\%) respectively. Regarding the Tumor appearance on cystoscopy it was 121(89.62\%) papillary and $14(10.38 \%)$ solid appearing tumors in Group A and 108(80\%) papillary and 27(20\%) solid appearing tumours in Group B.

On histopathology some tumors turned out to be low grade i.e. 81(60\%) after first presentation and $54(40 \%)$ low grade with recurrence in Group-A, while in Group-B, 73(54.07\%) were low grade tumors on first presentation and 62(45.93\%) were low grade tumors with recurrence. Regarding the TNM staging, the tumors with Ta stage were $108(80 \%)$ and T1 were $27(20 \%)$ in group-A. Stage Ta tumors were 99(73.33\%) and stage T1 were $36(26.67 \%)$ in Group-B.

In case of local side effects of BCG, dysuria was observed in 74 patients. Low grade fever was noted in 37 patients. Dysuria and fever settle 
within 48 hours and do not need any particular management apart from standard painkillers and anti-spasmodic. Patients with persistent fever were treated with anti-tuberculous therapy for six months.

Only 5 patients developed rigors after BCG instillation and those were treated with antihistamine. Frequency was observed in 68 patients. Urgency and nacturia were seen in 13 and 21 patients respectively. Irritative bladder adverse effects associated with Onco TICE administration were managed with anti-cholinergic and antiinflammatory.

Three patients developed macroscopic haematuria. Sixty three patients did complaint of malaise/fatigue and only 05 patients were observed with skin rash which reflected hypersensitivity reaction and were treated with anti-histamine. Flu like symptoms was noted in 39 patients and treated them symptomatically.
One patient developed BCG sepsis on the $3^{\text {rd }}$ day of BCG instillation and was treated with isoniazid and rifampicin.

There were 27 patients who developed frequency and dysuria after Mitomycin instillation which was resolved after a few days antibiotics. Haematuria were noted in 2 patients. Nine patients developed low grade fever which was treated with tablet Paracetamol. Palmer and genital rash was noticed in 11 patients and four patients developed itching sensation and advised them to cautious with the first urination so as to minimize splashing.

There were only $7(5.38 \%)$ in Group-A showing recurrence on follow up cystoscopy after intravesical BCG instillation as compared to $20(15.38 \%)$ with recurrence in Group-B, who received intravesical Mitomycin-C. The Recurrence at first year follow-up in both groups showed a significant difference $(p<0.05)$.

\begin{tabular}{|l|c|c|c|c|}
\hline \multicolumn{1}{|c|}{ Symptoms } & \multicolumn{2}{|c|}{ Group A } & \multicolumn{2}{c|}{ Group B } \\
\hline Painless Haematuria & No. of Patients & $\%$ & No. of Patients \\
\hline Clot Retention & 120 & 88.89 & 127 & 94.07 \\
\hline Urgency, Dysuria, Frequency & 82 & 60.74 & 12 & 0.89 \\
\hline Microscopic haematuria & 08 & 05.92 & 01.48 & 0.74 \\
\hline
\end{tabular}

Table-I. Percentage of patients according to symptoms in both groups

\begin{tabular}{|c|c|c|c|c|c|}
\hline \multirow[t]{2}{*}{ Site of the Growth } & \multicolumn{3}{|c|}{ Group A } & \multicolumn{2}{|c|}{ Group B } \\
\hline & No. of Patients & & & No. of Patients & $\%$ \\
\hline Right lateral wall & 81 & \multicolumn{2}{|c|}{60.00} & 49 & 36.29 \\
\hline Left lateral wall & 28 & \multicolumn{2}{|c|}{20.74} & 47 & 34.81 \\
\hline Posterior wall & 09 & \multicolumn{2}{|c|}{06.67} & 14 & 10.37 \\
\hline Bladder Neck & 03 & \multicolumn{2}{|c|}{02.22} & 06 & 04.44 \\
\hline Vault & 03 & \multicolumn{2}{|c|}{02.22} & 03 & 02.22 \\
\hline Multiple sites & 11 & \multicolumn{2}{|c|}{08.14} & 16 & 11.85 \\
\hline \multicolumn{6}{|c|}{ Table-II. Site of the growth in group A and group B } \\
\hline & Recurrence (+ve) & \multicolumn{2}{|c|}{ Recurrence (-ve) } & P-Value & Significance \\
\hline Group A & $5.38 \%$ & 123 & $94.61 \%$ & \multirow{2}{*}{0.001} & \multirow{2}{*}{ Highly significant } \\
\hline Group B & $15.38 \%$ & 110 & $84.62 \%$ & & \\
\hline
\end{tabular}




\section{DISCUSSION}

Bladder tumor is a common illness presenting to urological discipline across the globe. It is associated with significant mortality as well as morbidity. Although there has been tremendous research in early detection of TCC bladder and break trough has been established in controlling the clinical risk factors in terms of preventing the recurrences resulting in improvement in quality of life, lesser hospital stay and better cost effectiveness. However there has been no major success regarding the intravesical therapy in term of recurrence.

The strength of our study is that it is first study in present set up that is addressing complete spectrum of disease. The weakness of our study is that we could only follow the patients for one year; while such patients need long term follow up. The mean age of the patients in our study for group A and group B was $50.0 \pm 13$.1 and 52.3 \pm 12.9 years respectively. This observation is also consistent with other international studies that have evidence that this tumor is commonly present in $5^{\text {th }}$ and $6^{\text {th }}$ decade of life. ${ }^{12}$ In another study by Blaszyk $\mathrm{H}$, et al, the average age of the patients was 70 years. ${ }^{13}$

Bladder cancer is more common in male than female, with a worldwide man/woman ratio of $10: 3 .^{14}$ In our study, the male to female ratio was $3: 1$ which shows that this tumour is more common in males than in females. In the study by Blaszyk $\mathrm{H}$, et al, the male to female ratio was $3: 1 .{ }^{13}$ Result of our study is same to international studies. This ratio was somewhat closer to that of American ${ }^{15}$, British ${ }^{16}$ and Australian studies. ${ }^{17}$

The comparatively high incidence in males may be due to the more exposure to different carcinogens in relation to smoking and occupational exposure because in our set up females are restricted to home and it is the male who earns the living. Smoking in female is also uncommon in our part of world. Women also come to doctor late in their stage of the disease mainly due to social taboos while men seek treatment earlier. ${ }^{18}$ had a $25.1 \%$ recurrence rate at $1 \mathrm{yr}$, compared with $25.7 \%$ in the short-term MMC group and $10.4 \%$ in those receiving long-term MMC. Recurrencefree rates in the second and third year were, respectively, $70.5 \%$ and $68.6 \%$ for short-term MMC, $68.5 \%$ and $65.5 \%$ for short-term BCG, and $88.3 \%$ and $86.1 \%$ for long-term MMC. ${ }^{19}$

In our research, the recurrence rate, In Mitomycin group after one year is $15.38 \%$ and in BCG group recurrence is $05.38 \%$ which is quite different from international data. The possible reason for this discrepancy could be complete resection, good intravesical instillation, proper stay time of therapy and follow up the patients.

Our study is implicated on the urologists who are involved in initial management of bladder tumors. More over as TCC is occupational hazard it is also implicated on public health authorities and legislative bodies for implementation of rules regarding compensation for the workers in different industries. We have observed that our patients present very late as compared western hemisphere. In our country, patient's presentation and diagnosis of disease is delayed more importantly due to ignorance of the early symptoms by patients, poverty, lack of health education and poor diagnostic facilities.

\section{CONCLUSION}

Bladder tumor is quite common in this part of world. Occupation may play a role, but the exact etiological factors are still to be determined. However smoking has definitive association with CA bladder. The patients are usually male in the $5^{\text {th }}$ decade of life painless haematuria is the commonest presenting symptom of the bladder growth. Intravesical instillation of On Co Tice BCG significantly decreases the risk of recurrence in patients with stage $\mathrm{Ta}, \mathrm{T} 1$, single to multiple papillary bladder cancer, in low grade $\left(G_{1}, G_{2}\right)$ tumours. So intravesical instillation of OnCo Tice BCG is recommended in all low grade tumor patients to reduce the recurrence rate and progression.

Copyright $(18$ Feb, 2021. 


\section{REFERENCES}

1. Jemal A, Siegel R, Ward E, Hao Y, Xu J, Murray T, Thun MJ. Cancer statistics, 2008. CA: a cancer journal for clinicians. 2008; 58(2):71-96.

2. Garry D, Peter GR, Carrol T. Urothelial carcinoma: Cancer of bladder, ureter \& renal pelvis. Smith's General Urology. 16Th ed. Boston: McGraw Hill, 2004; 324-45.

3. Ather $\mathrm{MH}$, Fatima $\mathrm{S}$, Sinanoglu $\mathrm{O}$. Extent of lymphadenectomy in radical cystectomy for bladder cancer. World journal of surgical oncology. 2005; $3(1): 43$.

4. Kurth $\mathrm{KH}$, Bouffioux C, Sylvester R, Van der Meijden AP, Oosterlinck W, Brausi M. Treatment of superficial bladder tumors: Achievements and needs. European urology. 2000; 37(3):1-9.

5. Chen $\mathrm{CH}$, Shun $\mathrm{CT}$, Huang $\mathrm{KH}$, Huang $\mathrm{CY}$, Tsai YC, Yu $\mathrm{HJ}, \mathrm{Pu}$ YS. Stopping smoking might reduce tumour recurrence in nonmuscle $\square$ invasive bladder cancer. BJU international. 2007; 100(2):281-6.

6. Langbein S, Haecker A, Badawi JK, Michel MS, Alken $P$. Early instillation in superficial bladder carcinoma. Current status. Der Urologe. Ausg. A. 2004; 43(12):1531-6.

7. Isbarn H, Budäus L, Pichlmeier U, Conrad S, Huland $H$, Friedrich MG. Comparison of the effectiveness between long-term instillation of mitomycin C and short-term prophylaxis with MMC or bacille Calmette-Guerin. Study of patients with non-muscleinvasive urothelial cancer of the urinary bladder. Der Urologe. Ausg. A. 2008; 47(5):608-15.

8. Traxer O, Gattegno B. Early postoperative mitomycin $C$ instillation: when and how? Progres en urologie: Journal de l'Association francaise d'urologie et de la Societe francaise d'urologie. 2004; 14(2):249-51.

9. Barghi MR, Rahmani MR, Moghaddam SM, Jahanbin $M$. Immediate intravesical instillation of mitomycin C after transurethral resection of bladder tumor in patients with low-risk superficial transitional cell carcinoma of bladder. Urol J. 2009; 3(4):220-4.

10. Clarke NS, Basu S, Prescott S, Puri R. Chemoprevention in superficial bladder cancer using mitomycin C: A survey of the practice patterns of British urologists. BJU international. 2006; 97(4):7169.
11. Patel AK, Chapple CR. Anatomy of the lower urinary tract. Surgery (Oxford). 2008; 26(4):127-32.

12. Genega EM, Porter CR. Urothelial neoplasms of the kidney and ureter: An epidemiologic, pathologic, and clinical review. Pathology Patterns Reviews. 2002; 117(1):36-48.

13. Blaszyk H, Wang L, Dietmaier W, Hofstädter F, Burgart LJ, Cheville JC, Hartmann A. Upper tract urothelial carcinoma: A clinicopathologic study including microsatellite instability analysis. Modern pathology. 2002; 15(8):790.

14. Sylvester RJ, van der Meijden AP, Oosterlinck W, Witjes JA, Bouffioux C, Denis L, Newling DW, Kurth K. Predicting recurrence and progression in individual patients with stage $\mathrm{Ta} \mathrm{T} 1$ bladder cancer using EORTC risk tables: A combined analysis of 2596 patients from seven EORTC trials. European urology. 2006; 49(3):466-77.

15. Khadra MH, Pickard RS, Charlton M, Powell PH, Neal DE. A prospective analysis of 1,930 patients with hematuria to evaluate current diagnostic practice. The J Urol. 2000; 163(2):524-7.

16. Messing EM, Madeb R, Young T, Gilchrist KW, Bram L, Greenberg EB, Wegenke JD, Stephenson L, Gee J, Feng $C$. Long $\square$ term outcome of hematuria home screening for bladder cancer in men. Cancer: Interdisciplinary Int J Am Cancer Society. 2006; 107(9):2173-9.

17. Tekes A, Eng J, Fishman EK, Wahl RL. Imaging of neuroendocrine tumors: Accuracy of helical CT versus SRS. Abdominal imaging. 2004; 29(6):696-702.

18. Samanic CM, De Roos AJ, Stewart PA, Rajaraman $P$, Waters MA, Inskip PD. Occupational exposure to pesticides and risk of adult brain tumors. $\mathrm{Am} \mathrm{J}$ Epidemiol. 2008; 167(8):976-85.

19. Friedrich MG, Pichlmeier U, Schwaibold H, Conrad $S$, Huland $H$. Long-term intravesical adjuvant chemotherapy further reduces recurrence rate compared with short-term intravesical chemotherapy and short-term therapy with bacillus CalmetteGuérin (BCG) in patients with non-muscle-invasive bladder carcinoma. Eur Urol. 2007; 52(4):1123-30. 


\begin{tabular}{|c|l|l|l|}
\hline \multicolumn{3}{|c|}{ AUTHORSHIP AND CONTRIBUTION DECLARATION } \\
\hline Sr. \# & \multicolumn{1}{|c|}{ Author(s) Full Name } & \multicolumn{1}{|c|}{ Contribution to the paper } & Author(s) Signature \\
\hline 1 & Khalid Hussain & Supervisor. & \\
2 & Muhammad Asif & Researcher. & \\
3 & Farooq Malik & Statistical analysis. & \\
4 & Munazza Yasmeen & Proof reading. & \\
5 & Maria Tariq & Proof reading. \\
6 & Attiq-ur-Rehman Khan & $\begin{array}{l}\text { Making performa \& Data } \\
\text { collection. }\end{array}$ \\
\hline
\end{tabular}

